PNL-2442

UC-60

\title{
Accuracy of Wind Power Estimates
}

by

J. C. Doran

J. A. Bates

P. J. Liddell

T. D. Fox

October 1, 1977

Prepared for the

U.S. Department of Energy

under Contract EY-76-C-06-1830

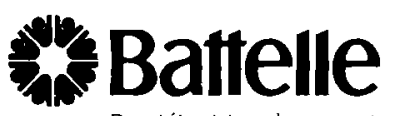

Pacific Northwest Laboratories 


\title{
NOTICE
}

This report was prepared as an account of work sponsored by the Unitec Stdses Government. Neither the United States nor the Department of Energy, nor any of their employees. nor any of their coniractors, subcontractors, or their employees, makes any warranty, express or implied, or assumes any legal liability or responsibility for the accuracy, completeness or usefulness of any information, apparatus, product or process disclosed, or represents that its use would not infringe privately owned rights.

The views, opinions and ccrclusions contained in this report are those of the contractor and do not necessarily represent those of the United States Covernment or the United States Department of Energy.

\author{
PACIFIC NORTHWEST LABORATORY \\ operated by \\ BATTELLE \\ for the \\ UNITED STATES DEPARTVIENT OF ENEPGY \\ Under Contract EY-75-C-06-785?
}

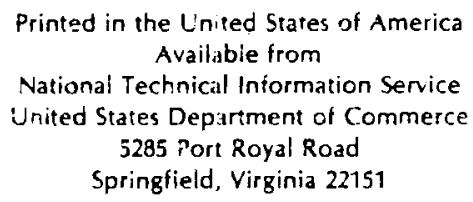

Price: Printed Copy \$_ "; Microfiche $\$ 3.00$

NTIS

- Pages Selling Price

$\begin{array}{ll}001-1) 25 & \$ 4.50 \\ 026-050 & \$ 5.90 \\ 051-075 & \$ 5.50 \\ 076-100 & \$ 5.93 \\ 161-125 & \$ 6.50 \\ 126-150 & \$ 7.00 \\ 151-175 & \$ 7.75 \\ 176.200 & \$ 8.50 \\ 201-225 & \$ 8.75 \\ 226-250 & \$ 8.00 \\ 25:-275 & \$ 10.05 \\ 276-300 & \$ 17.25\end{array}$


PNL-2442

$\mathrm{UC}-60$

\title{
ACCURACY OF WIND POWER ESTIMATES
}

\author{
by \\ J. C. Doran \\ J. A. Bates \\ P. J. Liddell \\ T. D. Fox
}

October 1, 1977

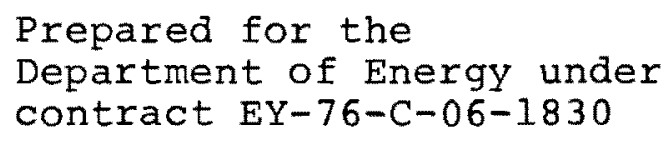

Battelle

Pacific Northwest Laboratories

Richland, Washington 99352 


\section{SUMMARY}

Several aspects of power estimation techniques for wind energy conversion systems are studied. The sampling rate at which data are collected, ranging from once every 2 minutes to once every 3 hours, does not appear to significantly affect the average power for recording periods of one season. Increased averaging times produce small underestimates $(<10 \%)$ of available power. The Rayleigh and Weibull distributions both give poor estimates of power for low mean wind speed situations, with the former being significantly worse. At higher wind speeds, both give good estimates, and the Rayleigh distribution is considerably simpler in form and application. A height extrapolation scheme for Weibull parameters is also investigated. Results are satisfactory for power estimates of ensembles of machines, but the scatter of values about the mean makes the method inappropriate for individual cases. 
INTRODUCTION. • . . . . . . . . . . . . . • . . 1

SAMPLING AND AVERAGING EFFECTS. • • . . . . . • . . . 2

DATA AND ANALYSIS. • . . . . . . . . . . . . . 3

POWER. . . . . . . . . . . . . . . . . . 10

ANALYTICAL DESCRIPTIONS OF WIND VELOCITY

FREQUENCY DISTRIBUTIONS • • • • • . . • • • • • . . . 13

VERTICAL EXTRAPOLATION. . . . . . . . . . . . . 18

REFERENCES. • • • . . . . . . . . . . . . . . 22 


\section{FIGURES}

1 Velocity Probability Densities for Twominute, One-hour and Three-hour Sampling Periods, Fall 1975 . . . . . . . . . . . . 5

2 Velocity Probability Densities for Twominute, One-hour and Three-hour Sampling Periods, Spring 1976 . . . . . . . . . . . . 6

3 Velocity Probability Densities for Twominute and One-hour Averaging Periods, Fall 1975 . . . . . . . . . . . . 7

4 Velocity Probability Densities for Twominute and One-hour Averaging Periods, Spring 1976 . . . . . . . . . . . . 8

5 Extrapolated Average Power Versus Measured Average Power for $200 \mathrm{~kW}$ WECS for Nuclear Power Plant and DOE Candidate Sites. Line Corresponds to Perfect Agreement . . . . . . . . 21

\section{TABLES}

1 Measured wind Characteristics for Various Sampling and Averaging Periods . . . . . . . . . 9

2 Theoretical Power Density and Extractable Power from Data for Various Sampling and Averaging Periods. . . . . . . . . . . . . 12

3 Average Power Estimates Based on Actual and Weibull wind Velocity Distributions $(46 \mathrm{~m})$. . . . 14

4 Weibull Parameters and Resultant Average Power Estimates. . . . . . . . . . . . 15

5 Ratios of Calculated to Measured Power Using Weibull and Rayleigh Distribution for $200 \mathrm{~kW}$ Machine.... . . . . . . . . . 17 


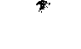

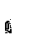

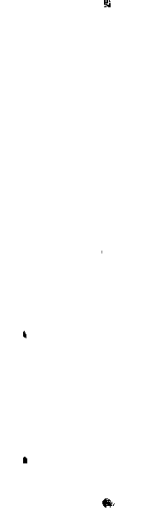


PNL-2442

$\mathrm{UC}-60$

ACCURACY OF WIND POWER ESTIMATES

\section{INTRODUCTION}

The estimation of the power which may be extracted from various wind energy conversion systems (WECS) frequently involves a number of approximations and assumptions, both explicit and implicit. These are required to compensate for deficiencies in the data which are often unavoidable. For example, extrapolation procedures are used in situations where wind measurements are available at one height, but information is required for another elevation. In this study, several aspects of such power estimation techniques are examined in order to provide an indication of the possible errors which may be associated with their utilization. Specifically, the effect of various sampling rates and averaging periods on the wind statistics is considered, the height extrapolation scheme of Justus and Mikhail (1976) is applied to a number of cases not previously studied, and a comparison of some features of the Weibull and Rayleigh distributions is made. In all cases, the evaluation of results is given in terms of power estimates for operating characteristics of hypothetical WECS. 


\section{SAMPLING AND AVERAGING EFFECTS}

In the collection and assimilation of wind data, a variety of recording procedures and instrumentation are available. Measurements relevant to the estimation of theoretically available or extractable wind energy may be divided into two principal groups characterized by time scales of a few seconds or less on the one hand and one or more hours on the other. The former group falls under the heading of "turbulence" and is important for questions of blade pitch control, structural fatigue, etc. The latter group provides the statistics which are most commonly used in assessing the available energy in the wind which may be realized by wind energy conversion systems, and is the subject of this section.

If wind velocity is regarded as a random variable, then in the limit of an infinitely long duration of data collection, the sampling rate at which data are collected would not be expected to have an effect on the resultant measured probability distribution function of velocity. If the collection period is too short, however, low frequency and random fluctuations may produce severe distortion in the empirically determined function. The averaging period over which measurements are taken also affects the statistics, since energy associated with frequencies greater than the reciprocal of the sampling period tend to be filtered out by the averaging process. If the form of the energy 
spectrum were known, this effect could be calculated directly, but such information is not generally available.

It therefore seemed useful to investigate the implications the above factors might have on the velocity probability density function and the resultant energy production of a hypothetical WECS. It was not intended that these investigations would generate specific, quantitative criteria which may be applied to all cases; the limited data base used and the extreme variability of wind characteristics that may be encountered would preclude this possibility. However, the results do indicate some of the problems which may arise, and provide estimates of the errors or uncertainties which may result. DATA AND ANALYSIS

Data were taken from the $10 \mathrm{~m}$ and $46 \mathrm{~m}$ levels of the Hanford tower. Wind velocities were averaged for one minute and sampled every two minutes, and recorded for a period of one year beginning in the fall of 1975 . Velocities up to $22.4 \mathrm{~m} / \mathrm{s}$ (50 mph) were detected; velocities above this value were ignored for this study. This produced no serious errors for two reasons: the frequency of occurrence of such high values was extremely small, and in the simulation of the power output from a hypothetical WECS, the cut-off or furling velocity was arbitrarily assumed to be $22.4 \mathrm{~m} / \mathrm{s}$.

The winds from two seasons were examined, covering a 54-day period in the fall of 1975 with approximately 38,000 
readings and a 91 -day period in the spring of 1976 with over 64,000 readings. Velocity probability density curves were constructed from readings taken every two minutes, from readings taken once every hour, and from readings taken once every three hours. The results are shown in Figures 1 and 2 for the fall and spring periods, respectively. In addition, to simulate the effects of a longer averaging period, as might be encountered with readings taken from strip chart recorders, 30 consecutive readings from each hour of data were averaged and used to generate another probability density curve. This is shown in Figures 3 and 4 as the "I hour averaging curve," together with the results from the readings taken every two minutes" ("2 minute averaging" curve). All curves shown are for the 46 meter level, but qualitatively similar results were cbtained for the 10 meter data.

As was anticipated, the smoothness of the probability density curve is severely degraded as the sampling rate decreases, although the general shape remains approximately the same. A similar loss of smoothness results from increasing the averaging time.

The average velocities, as well as the standard deviations about the average, may be determined from these probability density curves, and the results are given in Table 1.

As can be seen, despite the irregularities in the curves, the first two moments of the distribution are generally quite 


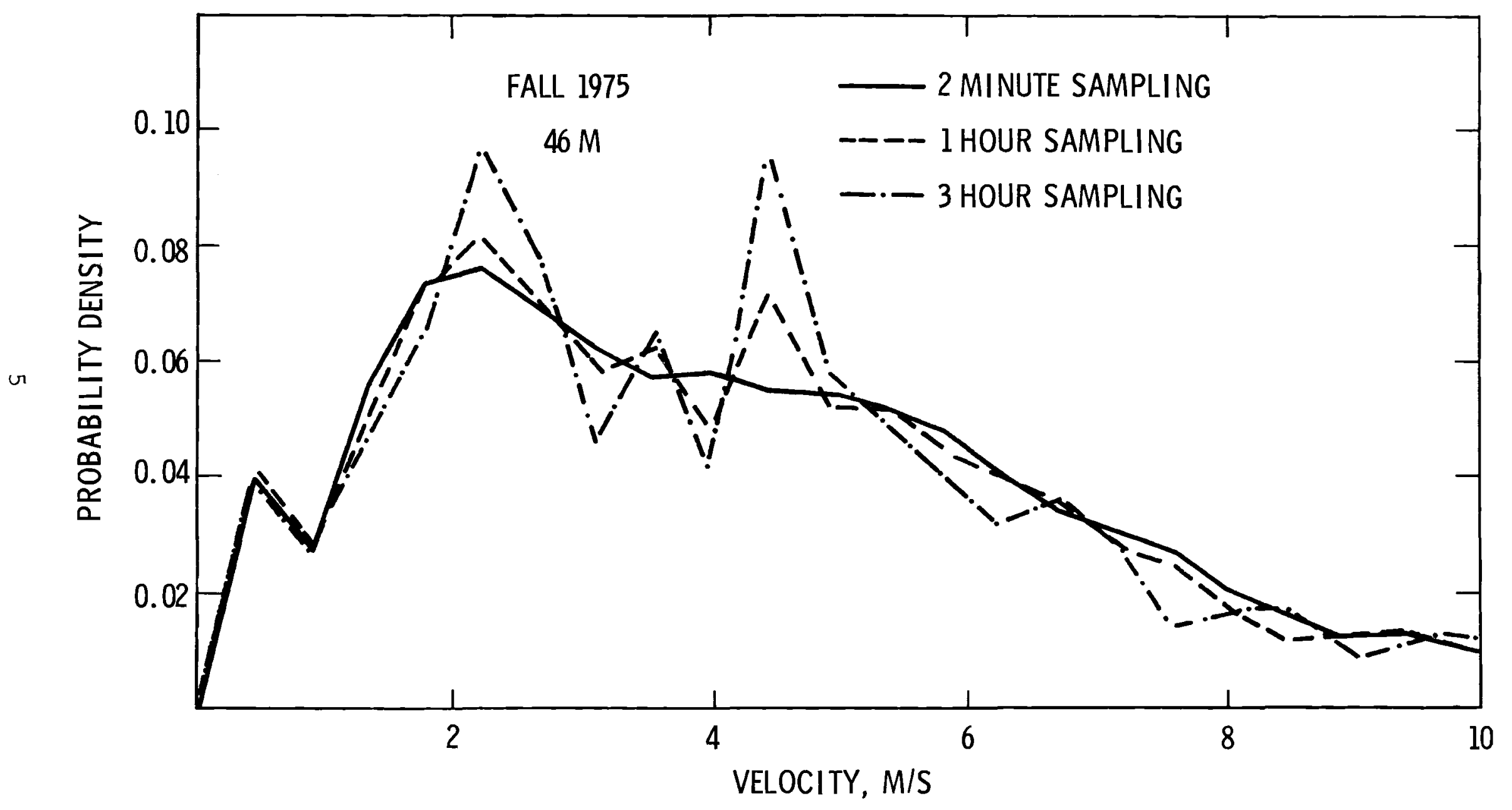

FIGURE 1. Velocity Probability Densities for Two-minute, one-hour and Three-hour sampling Periods, Fall 1975 


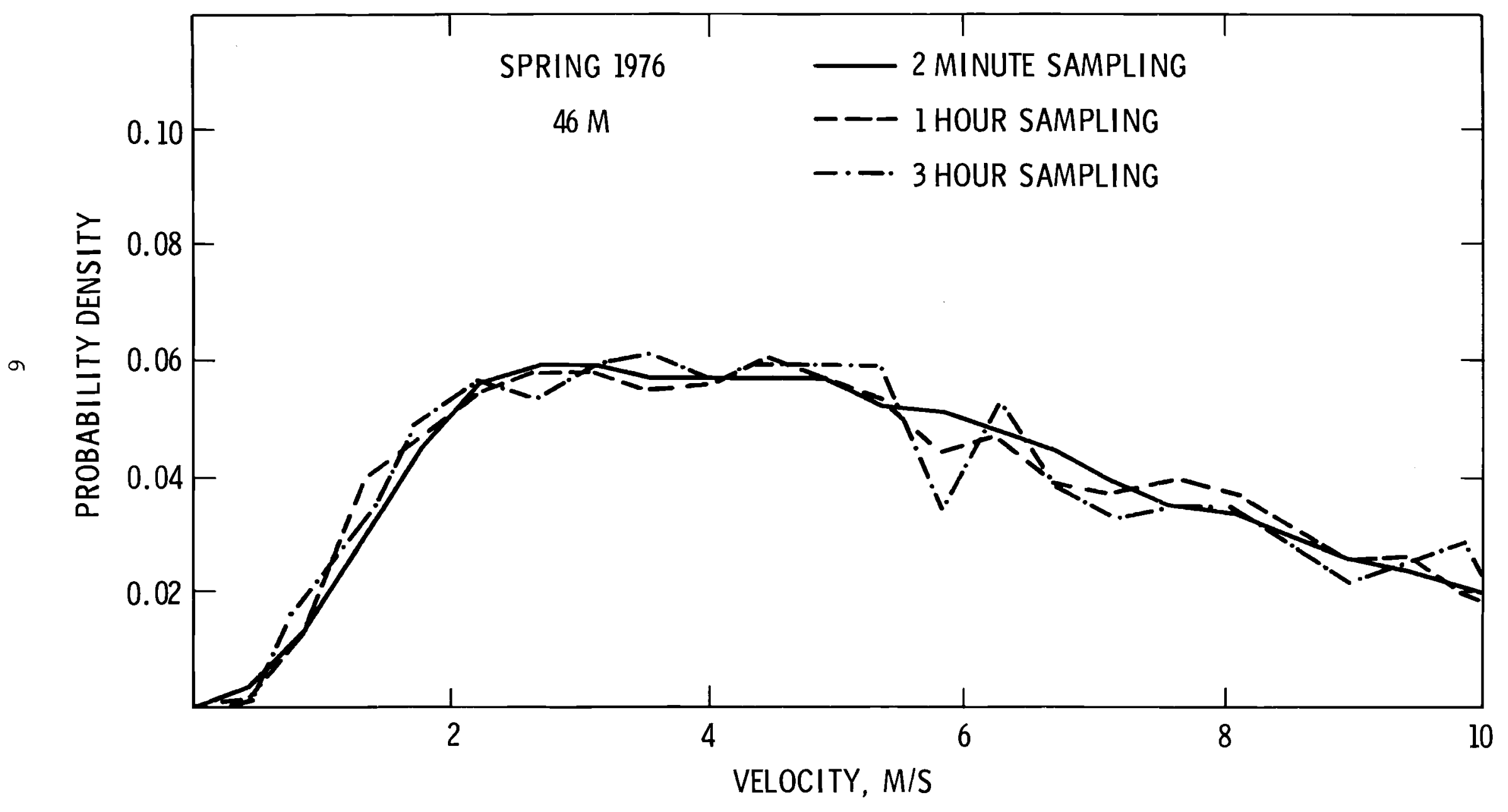

FIGURE 2. Velocity Probability Densities for Two-minute, One-hour and Three-hour Sampling Periods, Spring 1976 


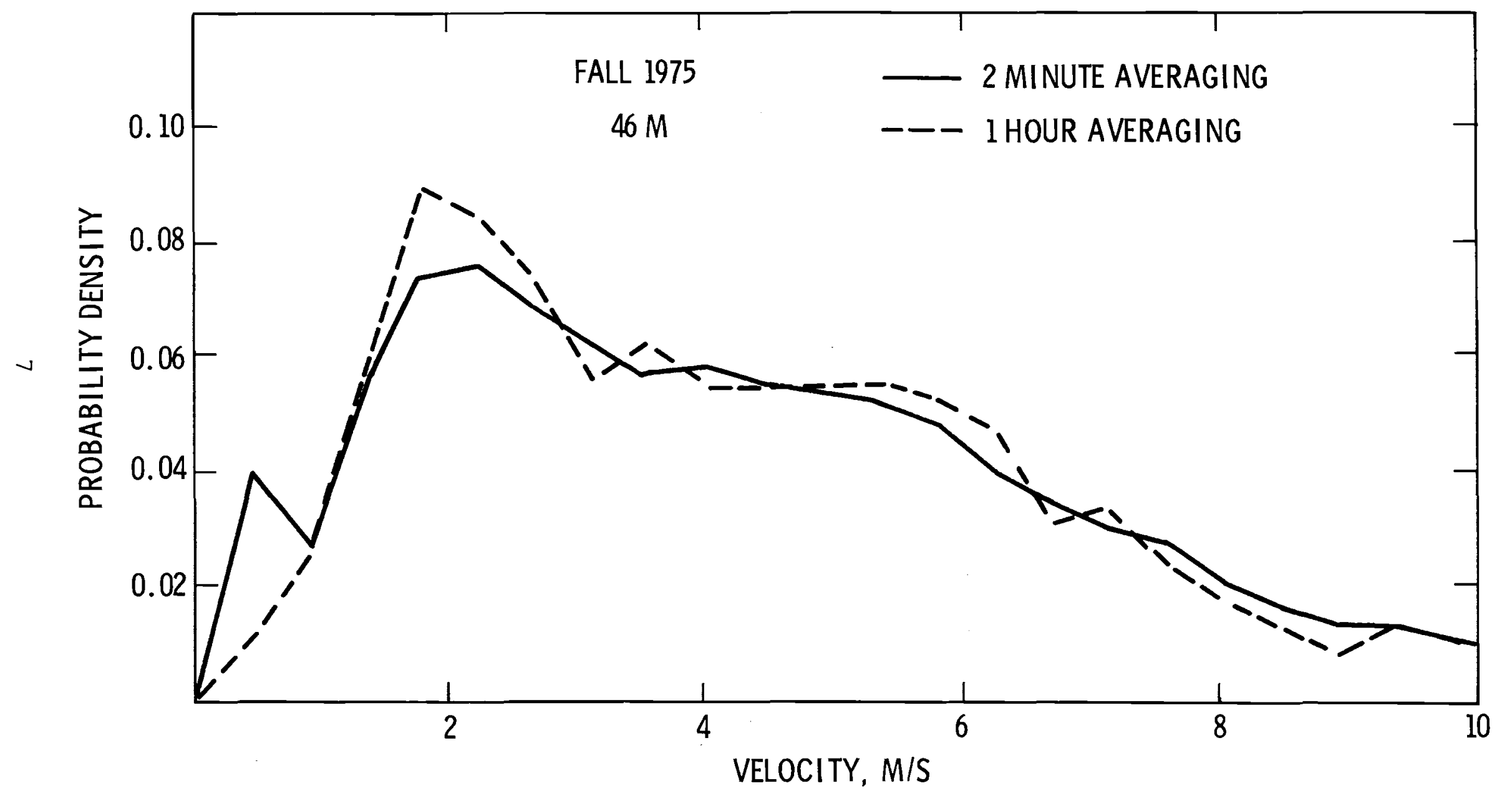

FIGURE 3. Velocity Probability Densities for Two-minute and Onehour Averaging Periods, Fall 1975 


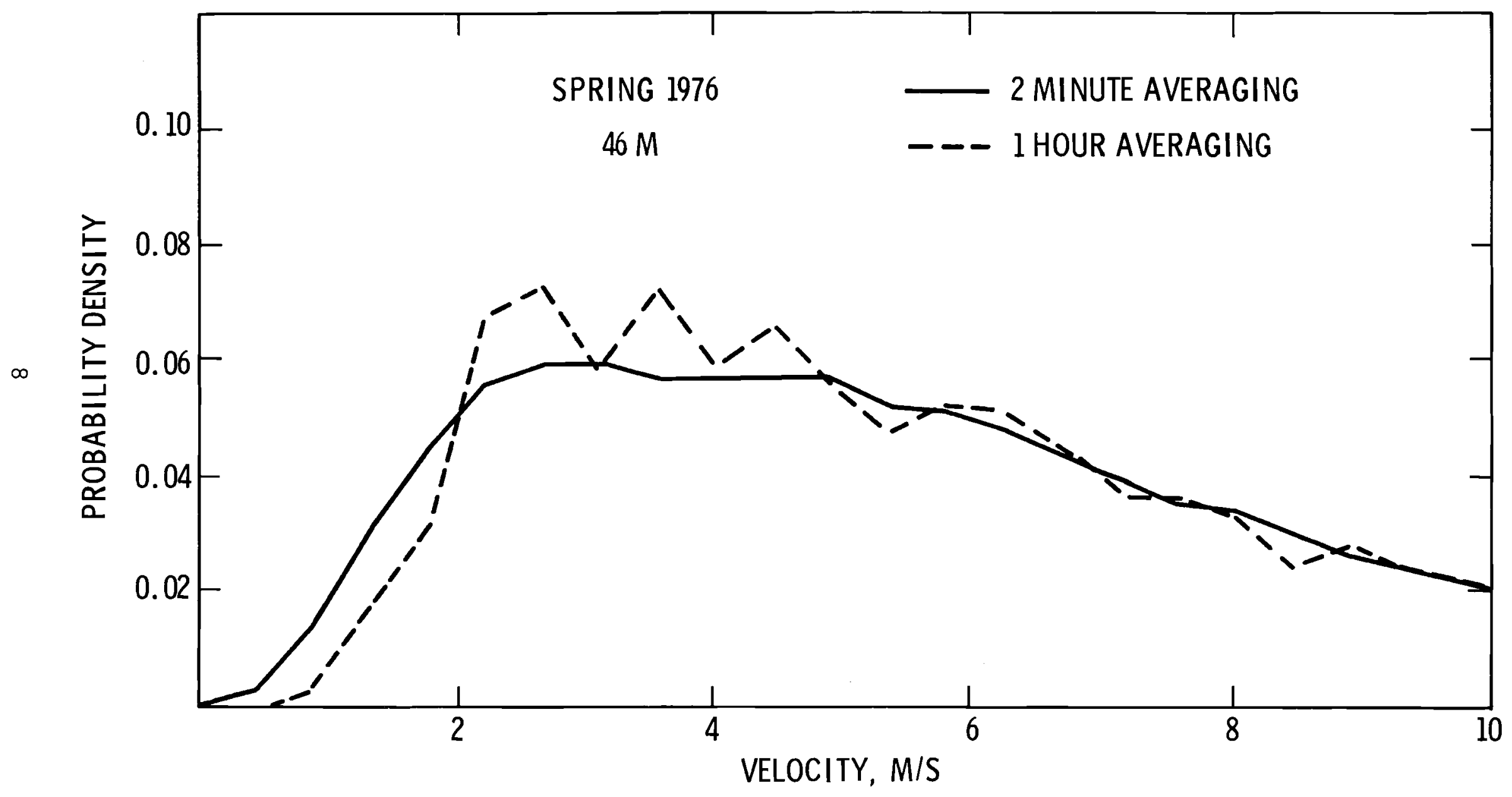

FIGURE 4. Velocity Probability Densities for Two-minute and Onehour Averaging Periods, Spring 1976 
TABLE 1. Measured Wind Characteristics for

Various Sampling and Averaging Periods

\begin{tabular}{|c|c|c|c|c|}
\hline Season & Height & & $\overline{\mathrm{v}}(\mathrm{m} / \mathrm{s})$ & $\sigma(\mathrm{m} / \mathrm{s})$ \\
\hline \multirow{4}{*}{ Fall 1975} & $10 \mathrm{~m}$ & 2 minute & 3.42 & 2.44 \\
\hline & & 1 hour & 3.41 & 2.42 \\
\hline & & 3 hour & 3.36 & 2.43 \\
\hline & & 1 hour avg. & 3.42 & 2.30 \\
\hline \multirow[t]{4}{*}{ Fall 1975} & $46 \mathrm{~m}$ & 2 minute & 4.51 & 3.28 \\
\hline & & 1 hour & 4.50 & 3.25 \\
\hline & & 3 hour & 4.47 & 3.25 \\
\hline & & 1 hour avg. & 4.50 & 3.08 \\
\hline \multirow[t]{4}{*}{ Spring 1976} & $10 \mathrm{~m}$ & 2 minute & 4.30 & 2.44 \\
\hline & & I hour & 4.29 & 2.29 \\
\hline & & 3 hour & 4.26 & 2.43 \\
\hline & & 1 hour avg. & 4.28 & 2.24 \\
\hline \multirow[t]{4}{*}{ Spring 1976} & $46 \mathrm{~m}$ & 2 minute & 5.48 & 3.17 \\
\hline & & 1 hour & 5.47 & 3.22 \\
\hline & & 3 hour & 5.43 & 3.16 \\
\hline & & 1 hour avg. & 5.46 & 2.95 \\
\hline
\end{tabular}

similar regardless of the particular sampling or averaging period used. The average velocities, $\bar{v}$, are virtually identical, as anticipated, with the maximum difference in any one season being less than $2 \%$. The two-minute sample values are always highest, while the three-hour sample values are lowest. For the standard deviation $\sigma$, the two-minute sample curve yields the highest values in three cases, while the one-hour average curves always yield the lowest ones. Differences between 
one-hour, three-hour, and two-minute sampling os are generally less than $2 \%$ (with one exception); differences between twominute and one-hour averaging curves range from 5.7 to $8.2 \%$. In this and all subsequent comparisons, it will be assumed that the two-minute averages give the "correct" results, and they will serve as the standards against which other results are measured.

$\underline{\text { POWER }}$

The differences in the probability density curves or statistical moments may be reflected in differences in estimated power production. There are two approaches to power calculations which have been used in the past. The first deals with the total power available in the wind, viz., $1 / 2 \rho v^{3}$, where $\rho$ is the density of air, while the second incorporates some of the limitations on the extraction of this power which arise from the performance characteristics of various machines. To study this latter effect, a hypothetical wECS with the following characteristics was assumed:

$$
\begin{aligned}
& \mathrm{v}_{\mathrm{O}}=4.2 \mathrm{~m} / \mathrm{s}, \\
& \mathrm{v}_{\mathrm{R}}=10.4 \mathrm{~m} / \mathrm{s}, \\
& \mathrm{V}_{\mathrm{C}}=22.4 \mathrm{~m} / \mathrm{s}, \\
& \mathrm{P}_{\mathrm{R}}=1.1 \mathrm{MW},
\end{aligned}
$$

where $V_{O}, V_{R}$ and $V_{C}$ are the cut-in, rated and cut-out speed, and $P_{R}$ is the rated power. Between $V_{0}$ and $V_{R}$ the power output was assumed to be given by 


$$
\mathrm{P} / \mathrm{P}_{\mathrm{R}}=\mathrm{A}+\mathrm{BV}+\mathrm{Cv}^{2} \text {, }
$$

where $A, B$ and $C$ are determined from the conditions

$$
\begin{gathered}
A+B V_{O}+\mathrm{CV}_{\mathrm{O}}^{2}=0 \\
\mathrm{~A}+\mathrm{BV}_{\mathrm{R}}+\mathrm{CV}_{\mathrm{R}}^{2}=\mathrm{P}_{\mathrm{R}}, \\
\mathrm{A}+\mathrm{BV}_{\mathrm{M}}+\mathrm{CV}_{\mathrm{M}}{ }^{2}=\mathrm{P}_{\mathrm{R}}\left(\mathrm{V}_{\mathrm{M}} / \mathrm{V}_{\mathrm{R}}\right)^{3},
\end{gathered}
$$

and

$$
\mathrm{V}_{\mathrm{M}}=\left(\mathrm{v}_{\mathrm{O}}+\mathrm{v}_{\mathrm{R}}\right) / 2 \quad \begin{aligned}
& \text { (Justus, Hargraves and } \\
& \text { Yalcin, 1976). }
\end{aligned}
$$

If $f(v)$ is the velocity probability density function, then the average power output is given by

$$
\bar{P}=\int_{0}^{\infty} f(v) P(v) d v,
$$

where $P(v)$ is the power output of the wECS as a function of velocity;

$$
\begin{array}{ll}
P(v)=0 & v \leq v_{0} \\
P(v)=P_{R}\left(A+B V+C V^{2}\right) & v_{0} \leq v \leq v_{R} \\
P(v)=P_{R} & v_{R} \leq v \leq v_{C} \\
P(v)=0 & v \geq v_{C} .
\end{array}
$$


Table 2 shows both the theoretically available power density and the extractable power for the hypothetical WECS, for $f(v)$ determined from sampling rates of once each two minutes, one hour and three hours, and also for a one-hour averaging period. As can be seen, sampling rate does not have a significant effect on the power estimates, even though the probability dersity curves for the slower rates may be considerably more irregular than those associated with the faster ones. However, the use of one-hour instead of two-minute averaging periods consistently results in underestimates of the power. These differences are not large $(<10 \%)$ and are of a conservative nature, so the use of such averages would not appear to be a cause of concern. Only the 46 meter values have been shown since this height corresponds reasonably closely to the hub height of typical large-scale machines.

TABLE 2. Theoretical Power Density and Extractable Power from Data for Various Sampling and Averaging Periods

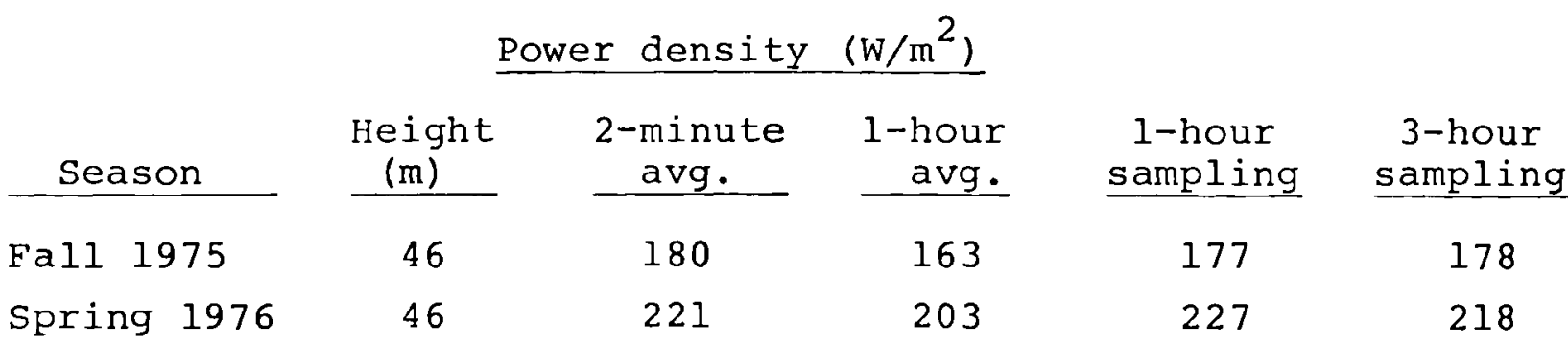

Average Extractable Power (kilowatts) for hypothetical WECS

$\begin{array}{llllll}\text { Fall } 1975 & 46 & 173 & 165 & 172 & 168 \\ \text { Spring } 1976 & 46 & 261 & 252 & 262 & 263\end{array}$




\section{ANALYTICAL DESCRIPTIONS OF WIND VELOCITY \\ FREQUENCY DISTRIBUTIONS}

Some attention has been given to the description of wind velocity frequency distributions by various analytic forms. In particular, the Weibull and Rayleigh distributions have been suggested as appropriate estimates of this quantity. Discussions thus far, however, have generally examined the goodness of fit of these functional forms without consideration of how accurate the resulting power predictions might be.

Weibull parameters, $k$ and $\mathbf{c}$, determine the velocity probability density function through the expression

$$
p(v) d v=\left(\frac{k}{c}\right)\left(\frac{v}{c}\right)^{k-1} \exp \left[-(v / c)^{k}\right] d v
$$

whereas the Rayleigh distribution is determined by a single parameter, the mean velocity $\bar{v}$;

$$
f(v) d v=\frac{\pi}{2}\left(\frac{v}{\vec{v}^{2}}\right) \exp \left[-\frac{\pi}{4}\left(\frac{v}{\bar{v}}\right)^{2}\right] d v
$$

This corresponds to the special case of the Weibull distribution when $k=2$.

Two series of tests were performed. In the first, the Weibull parameters were found from the $\bar{v}$ and $\sigma$ values given in Table 1, and the resulting power from the hypothetical WECS already described was determined and compared to the power calculated directly from the measured distribution. As implied 
earlier, two-minute and one-hour averaging time periods result in differences in $\mathrm{k}$ and $\mathrm{c}$ which ultimately appear as variations in the computed wind power. Table 3 summarizes these results for the 46 meter level; the 10 meter data showed similar behavior.

TABLE 3. Average Power Estimates Based on Actual and Weibull wind Velocity Distributions $(46 \mathrm{~m})$

\begin{tabular}{|c|c|c|c|c|}
\hline & & Power $(\mathrm{kw})$ & & \\
\hline & $\begin{array}{c}\overline{\mathrm{P}} \quad(2-\text { minute } \\
\text { avg. })\end{array}$ & $\begin{array}{c}\bar{P} \quad \text { (1-hour } \\
\text { avg.) } \\
\end{array}$ & $\begin{array}{c}\overline{\mathrm{P}} \quad \text { (Weibull } \\
\quad 2-\mathrm{min}) \\
\end{array}$ & $\begin{array}{c}\overline{\mathrm{P}} \quad \text { (Weibull } \\
1 \text {-hour } \\
\end{array}$ \\
\hline Fall 1975 & 173 & 165 & 185 & 177 \\
\hline Spring 1976 & 261 & 252 & 261 & 251 \\
\hline
\end{tabular}

The agreement is fairly good, and the use of one-hour instead of two-minute data for determining $k$ and $c$ did not have a significant effect on the power estimates.

In many cases, it may not be possible to extract both $\bar{v}$ and $\sigma$ from the available data, and $\mathrm{k}$ and $\mathrm{c}$ must be determined through some other means. Justus, Hargraves and Mikhail (1976) have shown how this can be done by means of a simple linear least squares routine relating $\mathrm{k}$ and $\mathrm{c}$ to the cumulative probabilities

$$
g\left(v_{i}\right)=\int_{0}^{v_{i}} f(v) d v=1-\exp \left(-\frac{v_{i}}{c}\right)^{k} .
$$


The $\mathrm{k}$ and $\mathrm{c}$ values thus determined depend upon the manner in which the velocity range of interest is divided, since the measured $f\left(v_{i}\right)$ reflect the irregularities in the probability density curve which is itself only approximately described by the Weibull distribution. An example of this is shown in Table 4. The heading "Interval" refers to the first velocity increment used in the least squares fit, i.e., $v_{1}$ in the notation of (14). As can be seen, changing this interval changes the $k$ and $c$ values and therefore the average power estimates. The effect here is not too large, but with more coarsely resolved increments it could be more significant. Any modifications would also be strongly dependent upon how well a Weibull distribution matched the actual data, so it is not possible to give general guidelines on a minimum acceptable velocity interval resolution.

TABLE 4. Weibull Parameters and Resultant Average Power Estimates

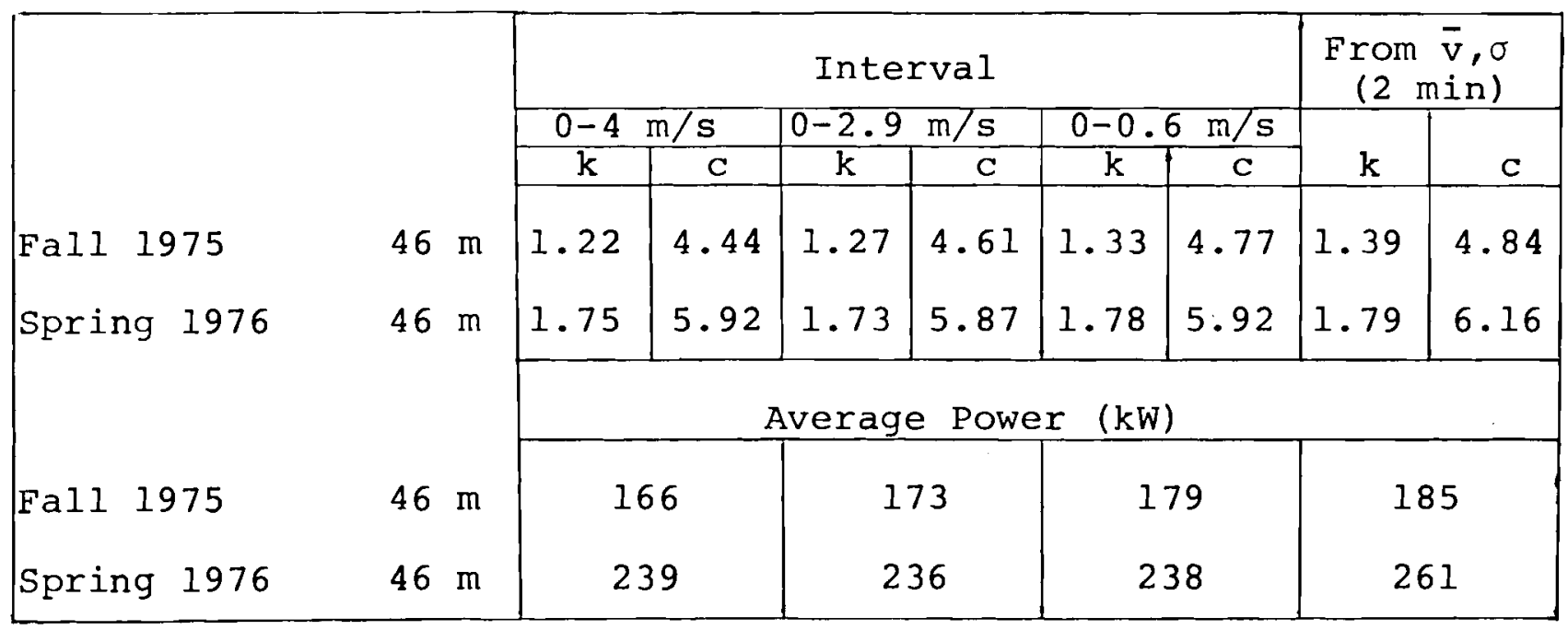


A second series of tests was carried out, utilizing the summarized nuclear power plant data of Verholek (1977), who concluded that those data were more satisfactorily represented in terms of a square-root normal distribution. For each station, a cumulative velocity distribution was examined graphically, and the velocities at which various values were relizea were then extracted from these graphs.

If $g_{i}$ represents the cumulative frequency at velocity $v_{i}$ ' the average velocity may then be approximated by

$$
\bar{v}=\sum\left(g_{i}-g_{i-1}\right)\left(\frac{v_{i}+v_{i-1}}{2}\right) \text {. }
$$

while the average power produced by a WECS with power output function $\mathrm{P}(\mathrm{V})$ is

$$
\bar{p}=\sum\left(g_{i}-g_{i-1}\right) p\left(\frac{v_{i}+v_{i-1}}{2}\right)
$$

This value may be considered the measured average wind power for these nuclear power plant sites.

Weibull parameters were also determined for each station and used in (7) and (12) to produce a second estimate of power. Finally, $\bar{v}$ was found from (15) and substituted into (13) and (7) to produce power estimates based on the Rayleigh distribution. Assuming (16) corresponds to the true value of the extractable power at a site, it is then possible to determine 
how well the Rayleigh and Weibull distributions reproduce the measured results.

The geometric means of the ratios of calculated to measured power are given in Table 5 for 8 velocity ranges for $\vec{v}$, assuming the wECS is a $200 \mathrm{~kW}$ machine, with $V_{O^{\prime}} V_{R}$ and $V_{C}$ equal to $4.47,10.73$ and $17.88 \mathrm{~m} / \mathrm{s}$ respectively. Results for other machines, viz., $100 \mathrm{~kW}$ and $1500 \mathrm{~kW}$ devices, were comparable. (Operating characteristics for these were $v_{0}=3.58 \mathrm{~m} / \mathrm{s}$, $\mathrm{V}_{\mathrm{R}}=8.05 \mathrm{~m} / \mathrm{s}, \mathrm{V}_{\mathrm{C}}=20.12 \mathrm{~m} / \mathrm{s}$ and $\mathrm{P}_{\mathrm{R}}=100 \mathrm{~kW}$, and $\mathrm{V}_{\mathrm{O}}=6.00 \mathrm{~m} / \mathrm{s}$, $\mathrm{V}_{\mathrm{R}}=13.00 \mathrm{~m} / \mathrm{s}, \mathrm{V}_{\mathrm{C}}=29.00 \mathrm{~m} / \mathrm{s}$ and $\mathrm{P}_{\mathrm{R}}=1500 \mathrm{~kW}$. )

TABLE 5. Ratios of Calculated to Measured Power, Using Weibull and Rayleigh Distributions for $200 \mathrm{~kW}$ Machine

\begin{tabular}{lcccc} 
Range of $\overline{\mathrm{v}}$ & $\begin{array}{c}\text { No. } \\
\text { Cases }\end{array}$ & $\begin{array}{c}\text { Rayleigh/ } \\
\text { Measured }\end{array}$ & $\begin{array}{c}\text { Weibull/ } \\
\text { Measured }\end{array}$ \\
\cline { 2 - 3 } $0.50-1.49$ & 1 & .00 & .56 \\
$1.50-2.49$ & 30 & .07 & .49 \\
$2.50-3.49$ & 45 & .44 & .66 \\
$3.50-4.49$ & 47 & .87 & .86 \\
$4.50-5.49$ & 14 & .99 & 1.01 \\
$5.50-6.49$ & 8 & 1.10 & 1.13 \\
$6.50-7.49$ & 3 & 1.09 & 1.09 \\
$7.50-8.49$ & & 1.13 & .91
\end{tabular}

As can be seen, the Weibull distribution is significantly better than the Rayleigh distribution at low average wind speeds, although neither is particularly good. At higher wind speeds, 
the differences between the two are minimal and the considerably simpler form of the Rayleigh distribution makes it a more attractive choice. It is quite probable that large wind machines would be installed only in areas with reasonably high wind velocities, and in such cases the Rayleigh distribution provides a simple and reliable means of estimating the average powsr output from WECS.

\section{VERTICAL EXTRAPOLATION}

The power law,

$$
\left(\frac{v_{2}}{v_{1}}\right)=\left(\frac{z_{2}}{z_{1}}\right)^{n}
$$

has often been suggested as a useful tool for the extrapolation of measured winds to a height where measurements are not available. The proper description of the height dependence of velocity has become even more important in recent years with the increased interest in wind power applications. Justus et al. (1976) have used the Weibull distribution to represent the wind velocity probability density function, and a set of formulae has been proposed (Justus and Mikhail, 1976) which allows extrapolations to be made of the Weibull scale factor $\mathrm{c}$ and shape factor $\mathrm{k}$. The relevant formulae, based in part on a power law for the wind profile, are 


$$
\frac{\mathrm{k}_{2}}{\mathrm{k}_{1}}=\left[1-0.0881 \ln \left(\mathrm{z}_{1} / 10\right)\right] /\left[1-0.0881 \ln \left(\mathrm{z}_{2} / 10\right)\right]
$$

and

$$
\frac{c_{2}}{c_{1}}=\left(\frac{z_{2}}{z_{1}}\right)^{n}
$$

where

$$
\mathrm{n}=\left(0.37-0.0881 \ln c_{1}\right) /\left[1-0.0881 \ln \left(\mathrm{z}_{1} / 10\right)\right]
$$

The subscripts 1 and 2 refer to lower and upper levels, respectively, $z$ is measured in meters, and $c$ in meters per second. These formulae were based on a rather limited set of data, and it was felt that additional tests of their accuracy were needed. The results presented below indicate that, while reasonable accuracy is obtained in the mean, the considerable scatter encountered requires that these extrapolation techniques be used with some caution.

The extensive compilation of wind data which summarizes wind records taken at 104 nuclear power plant sites (Verholek, 1977) includes 55 sites which had measurements at more than one level. Weibull parameters were determined from the data for each of these multi-level sites, and 41 locations were chosen at which the data were well described by a Weibull distribution. The criterion used was that the coefficient of determination for the least squares fit to the data (Justus, Hargraves and Mikhail, $1976)$ be at least 0.95 . These locations provided 62 pairs of 
levels to which the extrapolation formulae could be applied. In each case, $\mathrm{k}$ and $\mathrm{c}$ values were determined.

A wind energy conversion system with the operating characteristics of the $200 \mathrm{~kW}$ machine already described was assumed, and the average power output $\overline{\mathrm{P}}$ was computed using (7) and (12). For each pair of levels at a given site, power was computed for the upper level on the basis of the $\mathrm{k}$ and $\mathrm{c}$ parameters determined by actual measurements and for the values determined from the extrapolation formulae, (17)-(19). The results are shown in Figure 5, together with a line of slope 1 which represents perfect agreement. A least squares fit to the data yields a slope of 0.95 and a correlation coefficient near 0.9. While this is rather good, in $46 \%$ of the cases the calculated power differs from the measured power by $25 \%$ or more. Equations (17)-(19) are therefore most useful in the analysis of large ensembles of wind machines, but their application to collections of only a few sites or to individual locations could lead to substantial errors.

A number of the examples plotted have upper levels slightly in excess of $100 \mathrm{~m}$, a height for which (17)-(19) were not specifically intended. However, no significant differences were observed for these cases compared with those with smaller elevation. Calculations involving $100 \mathrm{~kW}$ and $1500 \mathrm{~kW}$ wind turbines gave results similar to those obtained for the $200 \mathrm{~kW}$ machine. 


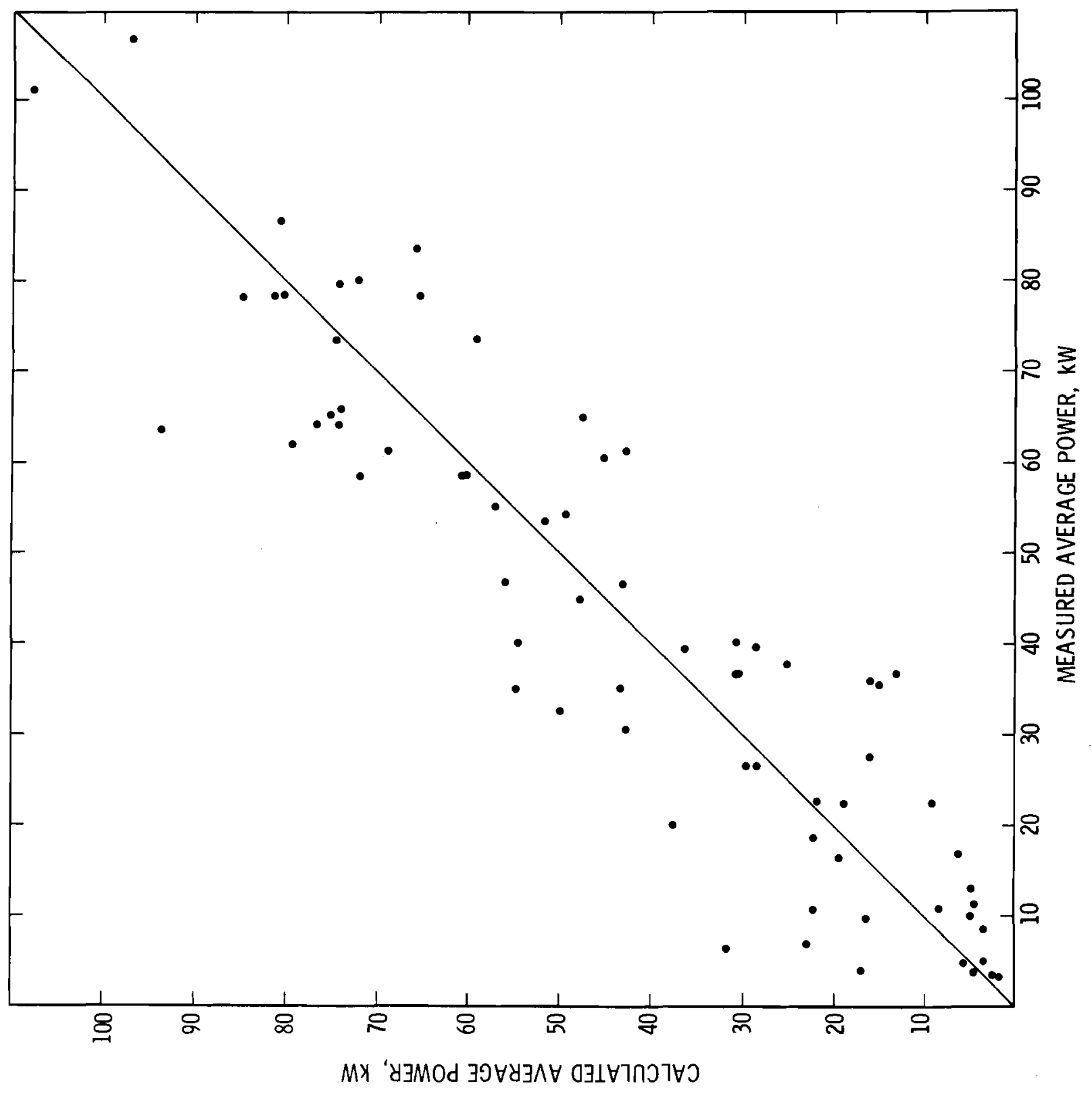

FIGURE 5. Extrapolated Average Power Versus Measured Average Power for $200 \mathrm{~kW}$ WECS for Nuclear Power Plant and DOE Candidate Sites. Line Corresponds to Perfect Agreement. 
Justus, C. G., W. R. Hargraves, and Amir Mikhail, 1976: Reference Wind Speed Distributions and Height Profiles for Wind Turbine Design and Performance Evaluation Applications, ORO/5108-76/4, UC60 (available from National Technical Information Service).

Justus, C. G., W. R. Hargraves, and Ali Yalcin, 1976: Nationwide Assessment of Potential Output from WindPowered Generators. I. Appl. Meteor., 15, 673-678. Justus, C. G. and Amir Mikhail, 1976: Height Variation of Wind speed and Wind Distribution Statistics. Geophys. Res. Lett. , 3, 261-264.

Verholek, M. G., 1977: Summary of Wind Data from Nuclear Power Plant Sites, BNWL-2220-WIND-4, Battelle, Pacific Northwest Laboratories, Richland, WA 99352. 


\section{DISTRIBUTION}

No. of

Copies

OFFSITE

1 ERDA Chicago Patent Group

9800 South Cass Avenue

Argonne, Illinois 60439

1 DOE Headquarters 600 E Street, N.W.

Washington, D.C. 20545

A. A. Churm

G. P. Tennyson

283 U.S. UOE Technical Information Center

No. of

Copies

ONSITE

2 U.S. DOE Richland Operations Office

H. E. Ransom

G. L. Liffick

102 Battelle-Northwest

C. E. Elderkin (80)

Technical Information (5)

J. V. Ramsde 11

Technical Publications

L. L. Wendel1

R. L. Drake

W. C. Cliff

D. S. Renne

J. C. Doran (5)

P. J. Liddel 1

R. L. Conley

E. H. Phinney

C. L. Simpson

H. Harty

R. L. Watts 